\title{
O POVO INDÍGENA SANÖMA/YANOMAMI E A TRILHA DE ADOECIMENTOS NA PANDEMIA DA COVID-19
}

SÍLVIA GUIMARÃES ${ }^{1}$

$U N B, B R A S I L$

https://orcid.org/0000-0002-2097-2355

\begin{abstract}
RESUMO: Este artigo pretende refletir sobre o atual momento pandêmico vivido pelos Sanöma, subgrupo da família lingüística Yanomami, os quais re-existem diante da violência estatal que amplifica o sofrimento desse povo ao não conter outras epidemias em seu território. Somam-se à covid-19, adoecimentos como a malária e verminoses que estão afetando-os, especialmente suas crianças. Para compreender este momento é importante nos reportar a epidemias passadas e suas implicações no cenário atual que a Covid-19 impõe. Os Sanöma têm colocado a vida e o cuidado no centro da luta contra esse estado de morte.
\end{abstract}

PALAVRAS-CHAVE: Sanöma, Yanomami, covid-19.

ABSTRACT: This article aims to reflect on the current pandemic moment experienced by the Sanöma, a subgroup of the Yanomami linguistic family, who re-exist in the face of state violence that amplifies the suffering of these people by not containing other epidemics in their territory. In addition to covid-19, illnesses such as malaria and worms are affecting them, especially their children. To understand this moment, it is important to report on past epidemics and their implications for the current scenario of Covid-19. The Sanöma have placed life and care at the center of the fight against this state of death.

KEYWORDS: Sanöma, Yanomami, covid-19.

\footnotetext{
${ }^{1}$ Professora do Departamento de Antropologia da Universidade Federal de Brasília, do Programa de PósGraduação em Ciências e Tecnologias em Saúde e do Mestrado em Sustentabilidade junto a Povos e Terras Tradicionais (MESPT). E-mail: silviag@unb.br.
} 


\section{Os Sanöma, a colonialidade e a produção de adoecimentos}

A primeira morte por Covid-19 entre indígenas no Brasil aconteceu com um jovem Yanomami no dia 9 de abril, em Boa Vista, no estado de Roraima (RR). Era um jovem ${ }^{2}$ de 15 anos que passava uma temporada na Comunidade Boqueirão para cursar o ensino fundamental. Essa comunidade fica na Terra Indígena de mesmo nome, onde vivem os povos indígenas Macuxi e Wapichana. Ele passou 21 dias com sintomas do novo coronavírus. Ao longo desse período, buscou atendimento médico e foi internado no Hospital Geral Regional (HGR), na cidade de Boa Vista, e ficou lá entre os dias 18 de março e 3 de abril. Após uma série de atendimentos inadequados, sem realização de teste, ele retornou à sua comunidade Helepe, localizada na Terra Indígena Yanomami. Sua situação se agravou e retornou ao HGR, onde faleceu por volta das $20 \mathrm{~h}$ do dia 9 de abril. A equipe do hospital não conseguiu estabelecer contato com Distrito Sanitário Especial Indígena Yanomami (DSEI-Y), o que aconteceu somente no dia seguinte. O DSEI-Y informou que o corpo do jovem foi sepultado uma hora após a sua morte no Cemitério Campos da Saudade pela Vigilância Sanitária de RR. Essa situação transparece a condição de indigente em que foi sepultado, sem o aviso aos familiares, violentando toda e qualquer garantia da família e do povo Yanomami de saber sobre o que foi feito com o corpo do jovem, os motivos desse enterro e suas condições. De acordo com Bruce Albert (2020), o sepultamento desse jovem nas condições que ocorreu trouxe à tona a falta de ética e empatia que move as autoridades sanitárias neste momento, configurando um ato desumano.

Esse jovem transitou pelo território dos povos Macuxi e Wapichana, Casa de Saúde Indígena ${ }^{3}$ do Distrito Sanitário Especial Indígena do Leste (DSEI-L), comunidade Yanomami Helepe, Hospital Geral de Roraima até ter o diagnóstico e falecer. De acordo com uma jovem liderança MacuxiWapichana, a possibilidade de o jovem ter sido contaminado por um motorista do DSEI-L é plausível, tendo em vista que o jovem Yanomami fazia tratamento e frequentemente era deslocado para instituições de saúde. Esse motorista havia retornado de uma viagem de Fortaleza (CE) um dos locus de contágio no país naquele momento por concentrar voos internacionais -, voltou a trabalhar e, logo em seguida, adoeceu e foi diagnosticado com covid-19. O questionamento dessa liderança é que nada foi feito com os profissionais e trabalhadores da saúde que

\footnotetext{
${ }^{2}$ Neste trabalho não iremos usar os nomes dos Yanomami e, também, de pessoas de outras etnias indígenas ou não-indígenas com o intuito de protegê-las. No caso dos Sanöma/Yanomami, os nomes não podem ser explicitados porque compõem parte de sua corporalidade e poderia ser usado por quem o lê, causando mal aos donos dos nomes. Esta pesquisa contou com o apoio da Universidade de Brasília por meio do edital COPEI-DPI/DEX n ${ }^{\circ} 01 / 2020$.

${ }^{3}$ As Casas de Saúde Indígena (CASAIs) fazem parte da estrutura dos Distrito Sanitários Especiais Indígenas (DSEI), que concretizam o Subsistema de Atenção à Saúde Indígena (SASI), o qual tem como objetivo garantir ações e programas de promoção e prevenção à saúde nas Terras Indígenas. Quando algum indígena precisa de atendimento na média e alta complexidade, serviços que estão localizados nas cidades, esse é deslocado para a cidade e fica alojado nas CASAIs. O SASI é parte do Sistema Único de Saúde (SUS) e foi criado a partir de uma demanda do movimento indígena, interessado em ter serviços da atenção básica nos territórios.
} 
retornaram de viagem; nenhum teste para covid-19 estava sendo realizado ou foi lhes solicitado que fizessem isolamento social. Ao mesmo tempo, o jovem Yanomami sofria de um quadro crítico de adoecimentos anteriores por malária e sua comunidade está localizada em uma região onde há garimpo. Portanto, existe também a possibilidade de ter sido contaminado por garimpeiros. Esse fato, ocorrido com esse jovem Yanomami, é um dos nós da trilha que iremos seguir neste artigo, revelando outros eventos que descortinam a ausência total de planejamento e gestão eficiente para conter o contágio, promover a saúde e a vida plena dos Yanomami.

Irei me debruçar aqui na trilha seguida especialmente pelos Sanöma ${ }^{4}$, subgrupo família lingüística Yanomami que acompanho há quase 20 anos. Neste momento da pandemia, estreitamos nossos laços e venho apoiando-os diante das várias violações que estão vivendo. Os Sanöma somam, aproximadamente, 3.000 pessoas. A região onde vivem é denominada pelos não-indígenas de Auaris, que se distribui por 45 microrregiões e está a uma distância de 2 horas e meia de voo até chegar à cidade de Boa Vista. Há variações nesse número de microrregiões diante da mobilidade desse povo em sua terra, que produz reconfigurações ao longo do tempo. Eles estão localizados no extremo norte da Terra Indígena Yanomami, na fronteira entre o Brasil e Venezuela, o que intensifica sua mobilidade.

Os Yanomami sempre souberam que a violência política estatal que causou várias epidemias em suas comunidades, abusos em seus corpos e invasões de seus territórios - estava ativa nos campos da burocracia de saúde, social, bem-estar e outras agências, como afirmam Kleinman, Das e Lock (1996) sobre a violência estatal e a produção de suas margens. Ainda de acordo com esses autores, o sofrimento social vivido por um povo pode vir de uma agenda de Estado ou estar em processos rotineiros de opressão, arruinando conexões de experiências coletivas e intersubjetivas. Processos racionais-técnicos e intervenções tecnologicas como "tratamentos" ou "programas de saúde" podem ser efetivos, mas também podem estar atrelados a respostas burocráticas que intensificam a violência. Esse cenário nos remete à colonização como definida por Aimé Césaire:

Ouço a tempesta. Falam-me de progresso, de "realizações", de doenças curadas, de níveis de vida elevados acima de si próprios. Eu, eu falo de sociedades esvaziadas, de culturas espezinhadas, de instituições minadas, de terras confiscadas, de religiões assassinadas, de magnificências artísticas aniquiladas, de extraordinárias possibilidades suprimidas. (1978, 25).

\footnotetext{
${ }^{4}$ Os Sanöma são um dos seis subgrupos da família lingüística Yanomami. Estão localizados no extremo norte da Terra Indígena Yanomami, no estado de Roraima, na fronteira entre Brasil e Venezuela. Essa engloba os estados de Roraima e do Amazonas. Ao todo os Yanomami somam, aproximadamente, 27.000 pessoas - os Sanöma são, aproximadamente, 3000 pessoas (SESAI, 2018).
} 
Para Césaire, colonização é coisificação e, nesse processo de desumanização, ninguém coloniza impunemente: quem coloniza é um grupo doente. A coisificação de Outros transforma todos em cadáveres. A colonização produz o horror e, na pandemia da covid-19, esses elementos se reuniram e se fizeram presentes. No caso dos Sanöma, eles estão buscando sobreviver em seus territórios diante de ações genocidas que os espreitam, quando, ao contrário, deveriam estar usufruindo de suas vidas livremente e de forma plena.

O genocídio indígena está relacionado à colonização, nos termos de Aimé Césaire (1978), ou à colonialidade, nos termos de Quijano (2005 e 2000), um não se faz sem o outro e, neste momento pandêmico, vemos esse genocídio se efetivar nas ações do Estado. De acordo com Quijano (2005 e 2000), temos que compreender a colonialidade como um processo que se estruturou na invasão das Américas, na construção do capitalismo colonial/moderno e eurocentrado e na organização de um padrão de poder mundial e que, hoje, se replica de múltiplas formas. $O$ genocídio indígena estava nos processos de escravização e evangelização desencadeados nos vários rincões do Brasil, nas armas biológicas e guerras que devastaram esses povos. E seguem nas invasões de garimpeiros, de madeireiros, de projetos desenvolvimentistas e de políticas anti-indígenas, que se expandem livremente pelos territórios indígenas.

Cada povo tem sua história e, ao longo do tempo, experiencia de maneira distinta os adoecimentos. Mas o que se observa na colonialidade é o ar comum do somatório da violência das doenças infecciosas, da usurpação territorial e da guerra, que buscou desfazer o tecido da vida social e fragilizar as relações éticas produzidas pelos indígenas que estruturam uma rede de reciprocidade com as várias criaturas da floresta. Esse modo de vida do colonizador voltado à produção dessa hegemonia de poder-saber é adoecido e produz figuras adoecidas. Novas identidades históricas e sociais foram construídas e a ideia de raça/etnia passou a ser naturalizada conjuntamente com o controle da subjetividade, dos modos de viver, do conhecimento e da produção de conhecimento. Pessoas adoecidas não conseguem ter soberania alimentar, são obrigadas a se submeterem a regimes de conhecimento da modernidade e de sua racionalidade. Ainda de acordo com Césaire:

Lançam-me em cheio aos olhos toneladas de algodão ou cacau exportado, hectares de oliveiras ou de vinhas plantadas. Mas eu falo de economias naturais, de economias harmoniosas e viáveis, de economias adaptadas à condição do homem indígena desorganizadas, de culturas de subsistência destruídas, de subalimentação instalada, de desenvolvimento agrícola orientado unicamente para o benefício da metrópole, de rapina de produtos, de rapina de matérias-primas. (1978, p.26).

Há um processo de transformação das vidas e das pessoas - essas passam a ser loucas, inaptas, sem compreensão, tuteladas, selvagens, 
bárbaras, que devem ser guiadas pelo colonizador. Tudo se refere a uma produção colonial doentia. Nesse jogo racista, Sueli Carneiro (2005) nos explica que etnia e raça passam a particularizar os sujeitos, desenhandoos como não-humanos, sendo Ihes atribuída a incompletude humana. A particularidade aqui de ser indígena o aprisiona ao seu grupo específico. Assim, o eu hegemônico rebaixa o estatuto do ser desse Outro.

O modo de vida indígena e sua rede de cuidado, a forma de manejo da floresta e de produção de alimento, construídos nos territórios, são afrontas ao capitalismo estatal que é uma versão da colonialidade. De acordo com Rita Segato ${ }^{5}$, para enfrentar um Estado de morte, como o atual governo federal, é preciso colocar no centro da luta a vida, mas uma vida solidária, no sentido de buscar decisões coletivas e refletir coletivamente, se abrir para um devir indígena. Por isso, o mundo indígena é um obstáculo ao capital estatal, que planeja invadir e impor grandes projetos aos territórios indígenas. Apresenta-se como um local de resistência, que escapa dos controles dessa instância por ser radicalmente comunitário. Formas familiares e comunitárias de vida, de organização política e alimentar visam outras civilizações e, para colonização, é essencial desarticular essa vida comunitária.

Como afirma Ailton Krenak, no documentário Guerras do Brasil ${ }^{6}$, os povos indígenas fizeram esses grandes jardins que são as florestas, como, por exemplo, a Mata Atlântica encontrada pelos primeiros portugueses. E isso ocorreu devido ao modo como estabeleceram relações éticas - base dessas relações comunitárias - com os seres da floresta, com os rios, com a terra, com os animais, etc. Os Sanöma vivenciam essa ética da moderação que é orquestrada pelos xamãs na floresta Amazônica. Esses cuidam para que os Sanöma transitem por determinados territórios, façam suas caçadas, pesquem, mas sem provocar o genocídio de qualquer criatura. Por conseguinte, fazem isso de forma moderada - caso contrário, esse acordo ético estabelecido entre essas diversas criaturas se quebraria e uma guerra ou revides por meio de adoecimentos aconteceriam. A vida Sanöma, como de vários outros povos indígenas, seguem essa ética da moderação também no cotidiano, por meio de ações conjuntas. Os escritos de María Puiz de la Bellacasa (2012) nos inspiram a falar de uma "ética do cuidado". Essa ética do cuidado ou "pensar com o cuidado", se refere a um conhecimento situado, significa que saber e pensar são inconcebíveis sem uma multidão de relações que também tornam possíveis os mundos com os quais pensamos. Na esteira do argumento da autora, é possível ver a vida indígena se fazendo em relações de pensar e saber que exigem cuidado. Ações práticas cotidianas são ético-afetivas vitais que se envolvem com problemas inevitáveis de existências interdependentes e se fundamentam no cuidado. Essa concepção de cuidado está em uma exigência ontológica de relacionamento nos mundos, como uma força relacional movendo

\footnotetext{
5 Aqui trago a discussão de Rita Segato em sua fala no webinário onde aconteceu o debate sobre "Capitalismo y luchas contrahegemónicas en tiempos de pandemia", ocorrido no dia 8 de julho de 2020, no canal do youtube: WambraEc Medio Digital Comunitario.

${ }^{6} \mathrm{O}$ documentário Guerras do Brasil dirigido por Luiz Bolognesi, com a direção de Laís Bodanski e de Luiz Bolognesi, de 2018.
} 
construções das pessoas, pensamentos, conhecimentos, realidades. Não se refere à ética hegemônica que moraliza e naturaliza o cuidado.

Os primeiros portugueses que chegaram a essas terras estavam adoecidos, de acordo com Ailton Krenak no documentário, e planejavam adoecer a terra e pessoas. Esse projeto colonial se estabeleceu e atinge a contemporaneidade. De acordo com Davi Kopenawa (Kopenawa \& Albert, 2005), o chafurdar que os garimpeiros fazem, como porcos do mato, na terra onde os Yanomami vivem, fez exalar a xawara - fumaça do metal , que teve consequências na produção do novo coronavírus. Os Sanöma denominam essa fumaça letal de wazu, que é capaz de matar uma comunidade inteira.

Os Sanöma viveram e sofreram com a epidemia de malária que foi desencadeada por uma invasão garimpeira no território Yanomami no final da década de 1980 (ALBERT, 1992). No caso do território dos Sanöma, na região de Auaris, não houvera uma concentração de garimpeiros como em outras regiões do território Yanomami, mas ocorreram conflitos armados e os Sanöma sentiram os efeitos do garimpo em suas terras. O wazu os alcançou e, hoje, eles fazem a leitura de que as diversas mortes que viveram vieram desse sopro letal dos garimpeiros, da malária (GUIMARÃES, 2015). Desse modo, em 1991, de acordo com Ramos (1991, p.11), "enquanto o total de mortes registradas por malária nas 15 áreas que compõem a totalidade do território Yanomami no Brasil foi de 110, entre os Sanumá o número chegou a 60 , ou seja, mais da metade de toda área Yanomami no Brasil". Entre 1987 e 1990, no auge da onda garimpeira, $14 \%$ de sua população morreu, principalmente, pela malária (RAMOS, 1991). Cabe perguntarmos sobre a dramática situação dos Sanöma sobreviventes desse genocídio.

Os Sanöma associam os garimpeiros às criaturas da floresta, os sai töpö (no singular sai the). Essas criaturas habitam lugares inóspitos, têm diversas formas corporais. Além disso, têm a capacidade de transfigurarse em outra criatura e voltar a ter sua forma corporal original. Algo que se manifesta de maneira surpreendente deve ser tratado com cuidado, o que os mantém em alerta. Por exemplo, um animal silvestre que se aproxima da aldeia e não teme a presença das pessoas, não será vítima de um caçador. Elas observam a estranha atitude do animal e concluem que se trata de um sai the transfigurado em caça. Eles passam a temer tal criatura e procuram afugentá-la, mas nunca a matar e comê-la. Acontecimentos estranhos na floresta também são sinais de perigo, pois podem ser os sai töpö em atividade. As relações dos Sanöma com os sai töpö são de grande cautela, pois eles temem a imprevisibilidade desses seres e sua capacidade de transfigurar-se em outras formas corporais momentaneamente. Os xamãs são os únicos que conseguem controlálos, mas jovens e inexperientes xamãs podem ser mortos ou ficar adoecidos pelas ações dos sai töpö. A principal característica desses seres é exatamente essa impossibilidade de se ter deles uma definição clara, de saber o que eles são ou podem vir a ser, de planejar uma interação com eles. Os Sanöma identificam uma dessas criaturas com a letalidade dos garimpeiros, especialmente com a violência como reagem à presença dos Sanöma. Um Sanöma me fez o seguinte relato: 
Um grupo de Sanöma saiu com seus vizinhos Ye'cuana para caçar, um sapuli (xamã Sanöma) foi com eles. Eles viram uma pessoa, despois o sapuli (xamã) dormiu e sonhou e viu essa pessoa com um facão. Aí depois, ele sonhou e viu essa pessoa indo embora, andando por ali. Outro dia, ele viu um relâmpago, na serra. Aí ele foi lá, encontrou essa pessoa. O sapuli (xamã) escutava a pessoa, aí, depois, a pessoa apareceu, ela sabia fazer tudo. Um Ye'cuana foi lá conversar com a pessoa, quando chegou lá, de repente, teve seu braço cortado. Os Sanöma chegaram, perto, escondendo seus braços. Só o sapuli conversou com ele, só o sapuli podia conversar com ele, e perguntou o que ele estava procurando por ali. Ele mostrou um monte de coisa em um buraco que tinha feito na terra, um buraco feio, tinha facão, panela. Os Sanöma e Ye'cuana pegaram tudo e a pessoa deixou eles irem embora, era muito perigoso. Era o sai the do garimpeiro, ele tem um chapéu, dente de ouro e roupa de ouro. As unhas, os olhos, o cabelo eram diferentes, tinha muitas coisas de ouro. No seu buraco, tinha muita coisa. Só o sapuli pode conversar com ele.

Essa letalidade dos garimpeiros e sua violência só pode ser controlada pelos grandes xamãs. Como criaturas imprevisíveis, podem oferecer presentes e, em seguida, cortar uma pessoa com facão. Fazem buracos na floresta, enchem de mercadorias e matam pessoas. Além disso, a malária foi produzida por eles e se espraia e se aproxima, adoecendo e matando os Sanöma. Rever esse tempo largo, míticohistórico, sobre epidemias vividas pelos Sanöma e suas relações com esses agentes causadores é importante para termos o cenário de como se encontram, hoje, e como receberam a covid-19.

Hoje, os Sanöma figuram nos estudos epidemiológicos nutricionais como um dos casos mais graves de prevalências de baixa estatura da mãe e baixo peso em crianças menores de cinco anos (BASTA E ORELLANA, 2020 e PANTOJA ET. AL, 2014). Esses estudos apresentam nexos causais que explicam a gravidade da desnutrição infantil Sanöma como relacionada à baixa estatura da mãe, que, por sua vez, seguindo o argumento dos artigos, viveram privação crônica alimentar ao longo da vida e na gestação, o que pode resultar em crianças com baixo peso para a idade e baixa estatura para a idade. E essas características de baixo peso e baixa estatura para a idade aumentam as chances dessas crianças se tornarem desnutridas (PANTOJA ET. Al, 2014 e ORELLANA ET. Al. 2019).

Não irei partir de generalizações e reunir os quase 27.000 Yanomami espalhados por sua Terra Indígena, vivendo diversos contextos de interações com os brancos. Especificamente, irei me referir aos Sanöma, que vivem uma soberania alimentar, mas, contraditoriamente, aparecem nessa descrição da desnutrição infantil grave. Distantes dos garimpos, eles sentiram e sentem os efeitos da 
malária que como o wazu lhes alcançaram. E sentem os efeitos dos vários adoecimentos que acometem suas crianças, isto é, de doenças infecciosas que chegam do trânsito de funcionários da saúde e dos soldados e suas famílias do Pelotão do Exército que vivem em seu território, próximo de algumas de suas moradias. Os Sanöma que transitam pela cidade também retornam com adoecimentos. Os Sanöma foram o subgrupo Yanomami que mais sofreu com a epidemia de malária dos anos de 1980 e 1990, como vimos anteriormente. A autonomia Sanöma de viver da sua produção alimentar vinda de suas roças, da coleta na floresta de plantas, cogumelos, méis e insetos, da pesca e da caça, dinamiza-se e não se abala com a presença de alimentos dos brancos. As cestas básicas ainda não se tornaram uma política estabelecida nesta comunidade e os alimentos dos brancos não entraram em uma avalanche por lá - a própria distância da cidade evita essa influência. No caso dos Sanöma, não é a má alimentação dos brancos que os enfraquece, mas sim ter seus corpos adoecidos por malária e tantas outras doenças dos brancos, que não lhes permite a vida digna na floresta e a soberania alimentar. O paradoxo desse processo é que a resposta do Estado às doenças dos brancos que avançam sobre seus corpos, impossibilitando de viver plenamente o manejo da vida, não está em um serviço de saúde eficiente, mas os gestores da SESAI sinalizam para a transformação de suas práticas de produção alimentar e regime alimentar. Kleinman, Das e Lock (1996) nos guiam nessa compreensão quando analisam que as ações do Estado amplificam o sofrimento que querem remediar e que causaram.

Diante desse cenário de colonização provocado pela invasão de seus territórios e adoecimentos que avançam e não são controlados, a mortalidade infantil entre os Yanomami, nos estudos epidemiológicos, também figura com taxas altíssimas: em 2010, foram registrados 109,2 óbitos por mil nascidos vivos (PANTOJA ET. AL, 2014). Comparando as taxas de mortalidade infantil das crianças Yanomami, em 2010, com as médias nacionais em relação às crianças indígenas e não indígenas, as taxas são 3,7 e 7,8 vezes superiores às médias indígenas e não-indígenas, respectivamente.

Sigo o argumento de Ailton Krenak quando discutiu dados demográficos das populações indígenas no webinário sobre Povos Indígenas e a Pandemia da Covid-19, organizado pela UNFPA, em 20 de maio de $2020^{7}$. Ailton Krenak analisa com cuidado os nexos causais que são apontados como expressão da vulnerabilidade indígena diante da covid-19, argumento este importante para avaliarmos a desnutrição infantil nesse cenário de adoecimento que acomete os Sanöma. Ele afirma:

A pandemia, ela traz para os nossos inimigos, inimigos históricos, uma espécie de garantia de que eles vão conseguir passar em cima da gente agora. Eu vejo esses dados como um alerta, dizer: "Olha como propositalmente a infraestrutura do serviço público se omitiu em relação a essa parte da população". Quando eu observo aquelas recomendações, por exemplo, de

\footnotetext{
${ }^{7}$ Webinário no youtube: https://www.youtube.com/watch?v=cRVdwss7BKc 
que os indígenas não têm saneamento. Eu não vou listar os itens, mas lá nos itens de saneamento, estão exatamente alguns equipamentos que não têm que ter na terra indígena. Eu sempre entendi que o povo indígena em situação de isolamento voluntário, são os que estão mais protegidos contra essa desgraça. Porque essa desgraça, de certa maneira, tem uma cor, ela é branca. E me perdoem usar uma expressão que pode ofender alguns de vocês, mas vocês estão entendendo o que eu quero dizer, quando eu digo, quando eu falo que essa, essa, eh, esse contágio ele vem, o vetor dele, ele se dirige, ele se dirige àquela parte da humanidade que sempre foi excluída. (...) Quando nós reclamamos uma infraestrutura do estado ao redor, ou entorno dessa população nós estamos entrando num campo de contradição, porque levar o saneamento e levar a infraestrutura do Estado brasileiro aos territórios indígenas, é a invasão dos nossos territórios, é a invasão dos nossos modos de habitar e ele nos coloca diante de um dilema: até quando nós vamos tratar a questão da assimilação forçada que o sistema capitalista instalado no Brasil promove em cima da vida dos povos indígenas através de políticas públicas, através de diferentes mecanismos de captura, até quando nós vamos tratar isso como um processo sem volta, como uma experiência que vai se concluir um dia com todos os povos indígenas, com seus territórios, com saneamento, com infraestrutura. Afinal de contas, isso seria a invasão dos nossos territórios, e seria a diluição das nossas formas de estar, de ser nos nossos territórios e, também, no mundo. Os povos indígenas têm um jeito de estar no mundo e esse jeito dos povos indígenas estar no mundo supõe um outro saber. Esses saberes estão sendo mobilizados agora pra produzir sobre esse momento da pandemia, eles são saberes que tem um retorno. Ele é um saber prospectivo, ele tá sempre se dirigindo no campo da ciência e é óbvio, pra buscar um conhecimento sobre um ponto além do momento que nós estamos vivendo agora. O saber desses povos que nós chamamos de povos indígenas, deles, está num lugar que eu entendo que é o aqui e agora. O conhecimento que nossos parentes vão aplicar para se proteger dessa pandemia, muito provavelmente não vai ter um elenco tão grande de ferramentas e dados como que esses estudos relacionam. Ele vai trabalhar fundamentalmente com a memória, com o saber ancestral e com práticas comunitárias de proteção. E são aquelas práticas comunitárias que nos fizeram ficar vivo até hoje diante de uma tentativa incessante de acabar com o povo indígena. 
Essa contradição ou paradoxo, como afirma Ailton Krenak, de ver o contexto de vulnerabilidade indígena como ausência de saneamento básico, de habitação, de trabalho assalariado, presença de água encanada, transporte, coleta de resíduos, enfim, em elementos que repercutem em contextos urbanos, pode ser uma armadilha para esses povos. A vulnerabilidade indígena está na invasão de seus territórios, na violência de garimpeiros e madeireiros, na expulsão de suas terras, na impossibilidade de ter uma rede educacional e de saúde que respeitem seus modos de viver e se adequem a eles. Essa vulnerabilidade está no fim de sua autonomia como povo que permite a vida plena em seus territórios com soberania alimentar. Modos de viver sedentários e toda a infraestrutura que necessitam rasgariam o tecido da vida social Sanöma, suas redes de relações intercomunitárias - que inclui o mundo dos brancos -, seus trânsitos respeitosos por território e duas estações do ano - seca e chuvosa -, os acampamentos temporários, suas tecnologias de manejo, sua vida comunitária em conjunto e suas práticas xamanísticas.

Os dados sobre a desnutrição infantil severa dos Sanöma devem ser analisados a partir desse processo de colonização afetando a vida dos Sanöma - reporto-me aqui às décadas recentes de 1980 e 1990, quando uma epidemia de malária avançou sobre o território Yanomami, fragilizou as vidas de toda uma geração e sua soberania alimentar. As mulheres Sanöma e as lideranças questionam a maneira como esses nexos causais desenham a desnutrição infantil, pois, nas narrativas dos gestores da saúde, como ouvi em reuniões em Brasília, as causas da desnutrição infantil recaem sobre os cuidados e produção de alimentos que realizam (Guimarães, 2019). A Secretaria Especial de Saúde Indígena (SESAI), tendo como base esses estudos epidemiológicos, tem questionado o modo de viver, o regime alimentar e cuidado com as crianças realizados pelos Sanöma e apontado tais elementos como a causa da desnutrição infantil. Seguindo o argumento de Sueli Carneiro (2005) acima exposto, para esses gestores, os Sanöma figuram como aqueles que não sabem gerir suas vidas, não pensam, não têm agência, não são humanos, mas como "coisas" que devem ser guiadas e ensinadas a viver. Os riscos de tais argumentos são perigosos quando o atual governo federal visa seus territórios e pretende transformá-los em terras de doentes com suas produções adoecidas, como vimos anteriormente no argumento de Césaire.

De acordo com os Sanöma, foi o demiurgo Omawö que lhes permitiu ter seus alimentos. Esses são do conhecimento dos Sanöma e não têm, para eles, qualquer tipo de associação com os dos brancos. Os alimentos típicos dos Sanöma, produzidos por eles, opõem-se aos alimentos que os brancos trazem, que estão empacotados, ensacados, enlatados e que, por isso, os Sanöma não veem ou conhecem o processo de produção. Os alimentos plantados nas roças, cultivados ou coletados na floresta, são os marcadamente Sanöma. Quando os brancos e sua parafernália, incluindo comidas, surgem na consciência mítico-histórica dos Sanöma, os seus alimentos não devem ser experimentados pelos xamãs, pois eles poderiam perder seus poderes. Os xamãs devem se 
alimentar daquilo que o demiurgo Omawö lhes ensinou a comer para que eles possam continuar a acionar os seres auxiliares, os hekula töpö, as pequenas criaturas que os auxiliam nas curas ou nas resoluções de conflitos.

Aqui vale uma pausa para falar do xamanismo Sanöma e da vida na floresta Amazônica. Nas sessões xamanísticas, com suas percepções alteradas, os xamãs inserem-se em uma outra dimensão, a dos seres auxiliares. Esses seres brilham, piscam como pequenas luzinhas, flutuam, aglomeram-se em volta dos xamãs e ocupam todos os lugares que a visão alcança. Os xamãs repetem o canto dessas criaturas hekula töpö, avisando quais deles estão presentes, esclarecem tudo o que acontece para a plateia que os escuta e que não é capaz de ver as pequenas criaturas. Há uma árvore do canto (hiiti amadi) na floresta onde esses seres auxiliares gostam de ficar; eles partem desse local para fazer uma morada no peito de um xamã. Os Sanöma falam que, quando caminham pela floresta e encontram essa árvore à noite, ela brilha intensamente e de lá ressoa um canto magnífico. Assim, eles sabem que os seres auxiliares estão por lá. A floresta é a morada dessas criaturas, da força do xamanismo que estrutura a vida Sanöma. Essas criaturas cuidam deles, dos animais e das plantas, das relações que mantêm com os seres da floresta e Ihes guiam. Por isso, os xamãs Sanöma falam que não há como substituir as plantas, as águas e seus alimentos, enfim: nada da floresta - do chão à copa das árvores da floresta, alcançando o céu -, nada pode ser substituído pela parafernália dos brancos, mas deve sim ser vivido, experenciado, dinamizado e transformado na ética da moderação ou ética do cuidado. Se acontecer um genocídio dessa floresta, eles estarão todos mortos, serão outros, não mais Sanöma/Yanomami. Os garimpeiros são uma ameaça a toda essa vida que pulsa e os mantém vivos.

Esse conhecimento Sanöma sobre a floresta e o manejo da vida entra no jogo da colonialidade, da desqualificação do conhecimento do Outro, como afirma Boaventura de Sousa Santos (1995) por meio do conceito de epistemicídio. Esse conhecimento indígena passa a ser inserido em um processo persistente de produção de indigência intelectual, deslegitimando-os como produtores de conhecimento. Sueli Carneiro (2005) afirma que esse processo consiste em ver os povos subjugados como sem capacidade cognitiva pela carência material e/ou pelo comprometimento da autoestima. Isto porque não é possível desqualificar as formas de conhecimento dos povos dominados sem desqualificá-los também, individual e coletivamente, como sujeitos cognoscentes. Por isso, para esses dois autores, o epistemicídio fere de morte a racionalidade do subjugado ou a sequestra. Busca mutilar a capacidade de pensar, criar e aprender, pela negação da racionalidade do Outro ou pela assimilação/colonização.

$\mathrm{Na}$ verdade, esse processo de adoecê-los já foi iniciado quando o garimpo avança e tem um crescimento exponencial e os serviços de saúde não são capazes de conter as doenças produzidas e introduzidas pelos brancos e as forças policiais não retiram os garimpeiros do território Yanomami. Ou quando os Sanöma são os culpados pela desnutrição infantil, pois não sabem, não conhecem sobre o cuidado com as crianças. 
Cenas da colonização se repetem: aquilo que viveram nas décadas de 1980 e 1990 está ativo hoje com a presença de mais de 20.000 garimpeiros no território Yanomami, quase alcançando o número total de Yanomami. No caso dos Sanöma, os efeitos do wazu dos garimpos somam-se a uma nova substância letal, a covid-19.

$\mathrm{Na}$ década de 1990, um conflito entre apoiadores dos Yanomami na contenção da malária e o Estado levou à expulsão desses apoiadores da área. Em 18 de maio de 2020, quando a Covid-19 fazia suas vítimas entre os Yanomami e muitas organizações não-governamentais ofereciam apoio aos Yanomami, o secretário da SESAl divulgou um ofício determinando que:

todas as referidas ações, que entendemos ser de muita valia, devem ter suas atuações formalizadas previamente junto à Secretaria de Saúde Indígena, para que esta tome ciência e, por conseguinte, monitorá-las e aprová-las, a fim de não configurar fuga às mencionadas normas, visando, ao final, garantir resultados de melhoria para a promoção de dados e informações que subsidiem o processo de gestão de políticas de saúde indígena.

Imediatamente, esse ofício recebeu várias críticas, pois visava um monitoramento e avaliação de ajudas humanitárias aos povos indígenas diante da situação de alastramento da covid-19 em territórios indígenas. Tal medida da SESAI afrontava a Convenção 169 da OIT, que recomenda a consulta aos povos indígenas sobre ações que afetam suas vidas. Em um momento de expansão da pandemia em que todos devem contar com a solidariedade, a SESAI impunha a tutela buscando gerir as vidas indígenas e as alianças solidárias que pretendiam estabelecer, retirando a autonomia dos povos indígenas. A SESAl se distanciava e ainda se distancia de sua obrigação de garantir o direito à saúde e apoio aos povos indígenas na defesa de suas vidas. Em 20 de maio, um novo ofício foi liberado, buscando amenizar o conteúdo do ofício anterior, mas o objetivo de controle dessas redes de solidariedade está posto.

A presença de garimpeiros em território Yanomami tomou um impulso exponencial ao longo dos anos de 2020 e 2021 com os incentivos do governo Bolsonaro no intuito de ocupar a Amazônia com a mineração e outras frentes econômicas. Como afirma a intelectual indígena maya k'iche Gladys Tzul Tzul (2020), a vida das comunidades indígenas se mostra frágil diante da covid, mas ao mesmo tempo suas ações projetam energia para que essa vida se refaça. Na pandemia, de acordo com a autora, por toda a América Latina nos territórios indígenas, o avanço de atividades extrativistas das mineradoras, dos madeireiros e dos grandes empreendimentos foi mantido. Essas atividades nunca pararam. Pelo contrário: se aproveitaram das normas de biossegurança para a Covid-19, como o isolamento social, para ampliarem seu avanço sobre as terras indígenas - foi isso que aconteceu com o garimpo na TI Yanomami. Além disso, de acordo com essa autora, o distanciamento social como prática de prevenção se mostra individualista e rompe com o 
comunitário, abrindo, assim, um terreno fértil para que o capital se imponha e limite as formas de organização comunitária.

Diante desse cenário explosivo provocado pela ação dos brancos em seu território, os Sanöma afirmam que a malária está descontrolada, as verminoses também estão deixando as crianças em uma situação crítica, as doenças respiratórias estão em uma crescente e há poucos profissionais de saúde em área para conter o agravamento dessa situação. Tudo isso tem levado vários Sanöma a serem removidos para a cidade com o estado de saúde agravado, requerendo o atendimento hospitalar. E a Casa de Saúde Indígena onde são hospedados tornou-se um epicentro de contágio da Covid-19 em 2020. A seguir iremos traçar outros nós dessa trilha da covid-19 vivida pelos Sanöma.

\section{Mortes, cloroquina e albendazol}

Até janeiro de 2021, mais de 80 Sanöma foram contaminados por covid-19. Eles se perderam nessa contagem diante da transmissão comunitária que, em setembro de 2020 , se iniciou em área e alcançou as comunidades de Auaris, Katarrinha, Hokolasimu, Korekorema e tantas outras. Antes da transmissão comunitária se efetivar, todos os Sanöma diagnosticados com covid-19 se contaminaram na CASAI do DSEI-Y, onde estavam fazendo algum tipo de tratamento. De acordo com os Sanöma, ao todo 4 bebês faleceram com suspeita de covid quando estavam em tratamento na cidade de Boa Vista. Outras mortes estão acontecendo nas comunidades com transmissão comunitária sem que explicações sejam dadas por parte do serviço de saúde. Os xamãs Sanöma buscam essas explicações, acionando os seres auxiliares.

Por parte da DSEI-Y vigora a subnotificação no número de contaminados, assim como de mortes, fato este denunciado pelas lideranças Sanöma por conta da adoção de uma estratégia de autoorganização, tal como fazem outras organizações indígenas, a fim de levantar os casos de contágio e as mortes por Covid-19 entre os seus membros.

O drama das mortes por covid-19 entre os Sanöma iniciou-se em abril de 2020, quando um bebê Sanöma havia falecido no hospital em Boa Vista e, com o início dos casos de Covid-19 na cidade, seu corpo ficou retido em Boa Vista e sua mãe retornou sozinha à sua comunidade. Foi dito à liderança Sanöma - ao presidente da associação indígena Sanöma - que a criança tinha uma suspeita de morte causada pelo novo coronavírus e por isso o corpo não poderia retornar. Logo após a morte do bebê, nenhuma liderança Sanöma ou a mãe foi informada sobre o paradeiro desse corpo. Somente após transitar buscando informação, a liderança conseguiu essa informação.

No mês seguinte, início de maio, uma mãe Sanöma é deslocada para Boa Vista com seu bebê, que precisava realizar tratamento de pneumonia. Esse veio a falecer em poucos dias. No final de maio, duas outras mães - uma delas moradora de uma aldeia na Venezuela - que buscaram tratamento no polo base localizado no lado brasileiro do 
território Yanomami, foram deslocadas para Boa Vista com o intuito de seus bebês passarem por tratamentos de saúde. As crianças eram todas menores de um ano e estavam com pneumonia em tal grau que requeria atendimento nos hospitais da cidade. Somente uma dessas mulheres, a que viera no início de maio, estava acompanhada de seu irmão - as outras duas vieram sem acompanhantes, estavam somente com seus bebês. Sem falar português e distantes de suas redes de apoio, essas mulheres adentraram o pior cenário da covid, o dos hospitais e da CASAl (Guimarães, 2020).

Sobre as redes de apoio dessas mulheres, vale mencionar que o matrimônio na vida Sanöma é marcado pela presença do genro na casa dos sogros ou em suas proximidades - vivem a uxorilocalidade. Desse modo, forma-se, na família extensa, uma rede feminina de cuidado, de jovens irmãs e mães, que vivem também próximas de suas tias maternas e filhas de suas tias. Em algumas situações, a jovem se muda para a casa do sogro - isso acontece quando esse tem força política maior que o pai da jovem ou quando esse já falecera. Os Sanöma vivem em casas retangulares onde as famílias extensas abrigam-se e configuram-se essas redes de apoio, de cuidado e de produção de alimento. As mulheres Sanöma não falam português, somente alguns homens se comunicam nessa língua. Quando essas mulheres se deslocam para Boa Vista, sem falar português e com seus filhos adoecidos, são lançadas em um local distante de seu território, de seu povo, em um lugar desconhecido, perigoso, devido aos vários contágios, à presença de inimigos e às ameaças de feitiços (MATOS E GUIMARÃES, 2016).

Nos hospitais, cada um dos quatro bebês falecera. As mães receberam a notícia das mortes, mas nada foi informado sobre 0 paradeiro dos corpos ou sobre a suspeita de covid. A seguir será descrito o cenário vivido pelos Sanöma com relação a três destes casos de morte envolvendo crianças.

Quando o segundo bebê morreu, no início de maio, a notícia se espalhou entre os Sanöma que estavam na CASAI e a liderança Sanöma, novamente, seguiu um périplo para saber do paradeiro do corpo da criança. A primeira suposição foi que o corpo do bebê estaria ainda no hospital. Os anciãos e as anciãs na comunidade souberam da notícia por meio do sistema de radiofonia e pressionaram a liderança para que ela cobrasse das autoridades o retorno do corpo do bebê ao território. Ele buscou informações no hospital, na CASAI e foi ao coordenador do DSEI $Y$, que o informou que a criança havia morrido de covid, foi enterrada $e$ só poderia ser exumada e retornar em três anos. A liderança informou à mãe e aos demais o que aconteceu. A mãe passou a fazer o seu choro lamurioso de luto pela morte do seu filho em meio a desconhecidos na CASAI e de forma tímida. Em alguns dias, ela retornou à Terra Indígena sem o corpinho do bebê.

No final de maio, a cena se repetiu: dois outros bebês que realizavam tratamento morreram. As mães retornaram à CASAI, onde se contaminaram de covid-19, sem saber do paradeiro dos corpos dos seus filhos. A primeira impressão que elas tiveram conjuntamente com a liderança foi que os corpos dos bebês estavam retidos no hospital. As 
mães, os anciãos e as anciãs na comunidade novamente exigiram o retorno dos corpos dos bebês para que pudessem realizar a cerimônia funerária. Mais uma vez a liderança seguiu por entre hospitais e a CASAI para saber sobre os paradeiros dos corpos e, na CASAI, foi informado que os bebês morreram de covid, foram enterrados no cemitério e só poderão ser exumados e retornar em três anos. A angústia invadiu as mães Sanöma que estavam na CASAI e suas famílias no território. Sem informações, explicações e compartilhamento de decisões, essas mulheres sofreram várias violências: o desaparecimento dos corpos de seus filhos, o enterro dos corpos e as decisões tomadas à revelia delas. A liderança se contagiou com a covid-19 quando estava por esse trânsito para descobrir o paradeiro das crianças.

Violações graves relativas aos direitos humanos dessas mulheres e desse povo se configuram com o desaparecimento e, em seguida, com o enterro dos corpos. Essas mulheres passaram a clamar por esses corpos, a liderança buscou por respostas e todos foram ignorados pelos serviços de saúde. Essas mães não receberam informações sobre o que fizeram com os corpos, sobre a causa da morte, não foram informadas sobre a gravidade da covid, não receberam os laudos indicando a causa da morte, não receberam os exames que comprovassem a infecção por covid e não participaram da decisão de ter seus filhos enterrados. Algo grave estava acontecendo. Albert (2020) define esse cenário como de desaparecimento político de corpos, uma grave violação de direitos humanos. Duas dessas mulheres falaram sobre a violência que viveram:

Eu sofri muito nesta gravidez, eu quero o corpo da criança de volta, que está aqui na cidade. Vocês, os maiores (lideranças), devem me devolver o corpo da criança. Vocês devem resolver de uma forma possível o retorno do corpo, porque eles faleceram dessa doença. Eu quero o corpo na comunidade. Eu estou sofrendo muito. Meu filho sofreu com a doença, agora, eu estou sofrendo. Eu tenho que levá-lo para a comunidade, meus pais, os velhos estão esperando. Temos que fazer a cerimônia funerária. Eu não quero deixar o corpo do meu filho aqui. Eu quero levar junto comigo, eu quero levar o corpo do meu filho, vamos juntos pra comunidade. Para ele ser queimado lá, para fazer a cerimônia funerária. Quero que seus chefes mandem o corpo do meu filho de volta. Eu quero leválo junto comigo. (Fala de uma das mães, em junho de 2020, traduzido para o português)

Se meu filho estivesse bem, eu não chamaria vocês. Nos mandaram de lá, mas quando chegamos aqui o meu filho pequenininho morreu. Então eu chamei vocês autoridades, eu não quero mais sofrer, eu não quero voltar sozinha. É muito difícil, estou muito triste! [...] Portanto, no dia 11 eu quero voltar junto com o corpo do meu filho, por isso chamei vocês, lideranças! 
[...] Eu chamei vocês autoridades, porque eu não quero mais sofrer! Meu filho pequeno morreu lá no hospital, então por isso estou chorando" (Fala de uma das mães em reportagem do Jornal Folha de Boa Vista, em junho de 2020, traduzido para o português) ${ }^{8}$

Para os Sanöma, as cerimônias funerárias são um elemento importante e estruturador de sua sociocomologia, pois visam um processo de transformação do morto (heno polepö de) para que ele siga o caminho da aldeia dos mortos, onde terá uma nova vida. O enterro realizado pelos brancos violenta essa forma de viver. A cerimônia Sanöma envolve a cremação do corpo do morto, a maceração dos ossos e o consumo das cinzas com um mingau de banana pelos parentes próximos em meio a uma grande cerimônia com a presença de aliados (GUIMARÃES, 2010). Ao longo da cerimônia, que pode perdurar por mais de um ano, o morto permanece por perto, tenta atrair os seus parentes vivos para sua casa, ou seja, quer transfigurá-los em mortos. Quando os Sanöma sonham, o morto oferece-Ihes a comida dos mortos. Se o Sanöma comer, transformar-se-á em morto. Quando as cinzas finalizam e há a conclusão da cerimônia, a metamorfose estará completa e o morto estará em sua nova morada, vivendo uma nova vida. Ele será esquecido e finda este ciclo da vida, e um novo se abre junto a outros Sanöma já falecidos.

Essa complexa cerimônia compõe o cosmos Sanöma, suas vidas e formas de se relacionar e se fazerem humanos. Os riscos de ter um corpo enterrado recaem sobre o morto, que não conclui seu ciclo, e sobre os vivos, por tê-lo tão perto. Não compreender as implicações dessa negação das cerimônias para a vida Sanöma revela o impulso colonialista dos serviços de saúde, quando não se abrem para compreensão de vidas e respeito à humanidade do Outro. Essa perspectiva é histórica do racismo, da colonialidade dos serviços de saúde que atuam com os Sanöma e sabem da existência das cerimônias funerárias, mas não as respeitam e as julgam algo menor diante do trabalho que realizam na saúde.

Os Sanöma se organizaram e construíram uma ampla rede de apoio, especialmente com o texto publicado no El Pais pela jornalista e escritora Eliane Brum (2020), o qual amplificou essa demanda e lançou essa violência em redes de movimentos sociais mais amplas. Após esse apoio amplo, conjuntamente com uma denúncia feita ao Ministério Público de RR, os Sanöma conseguiram reverter parte dessa situação quando as mães e o povo Sanöma foram informados sobre o que aconteceu com os corpos, quando o DSEI-Y foi ao território Sanöma explicar para as lideranças sobre a covid-19, suas formas de contágio e as regras de biossegurança. Mas ainda não se abriram para a possibilidade de o corpo ser tratado nas comunidades. Em conversa com Dario Kopenawa, ele me explicou que os Yanomami têm especialistas que cuidam das cerimônias funerárias, que dominam conhecimentos sobre como tratar o corpo do morto. E ele questiona por que os especialistas

\footnotetext{
${ }^{8}$ https://folhabv.com.br/noticia/CIDADES/Capital/Mae-yanomami-implora-para-retornar-a-comunidadecom-corpo-do-filho/66795
}

GUIMARÃES, Sílvia. O povo indígena Sanöma/Yanomami e a trilha de adoecimentos na pandemia da covid-19. Espaço Ameríndio, Porto Alegre, v. 15, n. 2, p. 16-37, mai./ago. 2021. 
médicos dos brancos não podem conversar com os especialistas Yanomami.

Após essa mobilização, dois corpos dos bebês retornaram, permitindo a realização das cerimônias funerárias e dois corpos ficaram enterrados na capital, pois testaram positivo para Covid-19. E ficou acordado que, em dois anos, os corpos irão retornar para a comunidade. No final de setembro de 2020, outro bebê e sua mãe foram deslocados para Boa Vista - a criança apresentava um quadro grave de pneumonia. Foi realizar um tratamento, contaminou-se pela Covid-19 e faleceu no hospital. Seu corpo também não retornou e foi enterrado em Boa Vista. Os serviços de saúde dos hospitais mudaram sua postura com a mãe Sanöma, pois, agora, disponibilizaram laudo médico referente à causa da morte e explicaram o procedimento para a mãe conjuntamente com a liderança Sanöma.

Ao longo dessa pandemia, a vida dos Sanöma foi marcada pelas mortes desses bebês, que seguiram o itinerário do adoecimento por pneumonia - não controlada nas unidades de saúde nas comunidades -, e, em seguida, se contaminaram pelo novo coronavírus nos hospitais e faleceram. Seus corpos mortos apresentaram o grande incômodo de terem sido enterrados, violando a cosmovisão dos Sanöma.

Essas mortes seguem acontecendo diante da grave situação de saúde na área indígena. A malária tem fragilizado famílias inteiras que adoecem e essas pessoas, pais e mães, não conseguem manter o cuidado de si e dos seus filhos. Os serviços de saúde na área onde vivem os Sanöma estão com um número reduzido de cinco profissionais para 3000 pessoas, distribuídas por 45 comunidades. Não é possível manter o tratamento da malária, que requer visitação e acompanhamento quando todos da família estão adoecidos. Além disso, os Sanöma denunciaram que não há alimentação para os pacientes ficarem sob a supervisão dos profissionais de saúde no denominado "hospital" do polo base. O tratamento de malária, no caso de bebês, pode levá-los a vomitar e eles precisam ser assistidos de perto pela equipe de saúde - por isso, precisariam ficar hospedados no "hospital" do polo, para que tenham o monitoramento de sua alimentação. Isso não tem acontecido na atual gestão porque o DSEI-Y não tem enviado alimentação para os pacientes que necessitam dessa supervisão no polo base.

Os Sanöma vivem, hoje, um cenário de descontrole da malária este ano, na comunidade do Kalisi, onde vivem 393 pessoas, 30 testaram positivo para malária; e na comunidade de Kolulu, onde vivem aproximadamente 334 pessoas, 100 testaram positivo para malária, nos poucos testes que foram feitos. De acordo com Nota da Rede ProYanomami e Y'ecuana $(2020)^{9}$, no DSEI-Y, o número de pessoas contaminadas pela malária se ampliou de 2018 para 2019 , indo de 9.738 para 14.827.

Logo após a violência do desaparecimento dos bebês contaminados e mortos por Covid-19, ao invés de buscar conter a proliferação de

\footnotetext{
${ }^{9}$ Nota Técnica para contribuir ao combate da covid na Terra Indígena Yanomami, produzida pela Rede de Pesquisadores e Apoiadores dos Povos Yanomami e Y'ecuana, de 12 de maio de 2020.
} 
doenças entre os Yanomami, em julho de 2020 a SESAI realizou uma "Missão interministerial de emergência em saúde pública de combate à pandemia da Covid-19 em populações indígenas de Roraima". Essa foi orquestrada pelo secretário da SESAI e aconteceu no território Sanöma e em outros locais da Terra Indígena Yanomami, provocando aglomeração de agentes públicos e jornalistas. Fizeram parte dessa missão o secretário da SESAI, o ministro da Defesa, representantes da Fundação Nacional do Índio (FUNAI), 21 profissionais de saúde da Marinha, Exército e Aeronáutica (12 médicos, 3 enfermeiras, 6 técnicos de enfermagem) e 18 jornalistas da imprensa nacional e internacional. Esse evento foi marcado por aglomeração e entrega de Equipamentos de Proteção Individual (EPIs) e milhares de comprimidos de remédios de cloroquina $(16 \mathrm{mil}$ comprimidos), azitromicina e prednisona.

O Ministro da Defesa, Fernando Silva, afirmou: "Cheguei lá agora. Tivemos uma operação com várias etnias. Nós não tivemos nenhum caso e o relato de aldeias mais longínquas é somente dois casos. Então, não é um caso de uma pandemia que está atingindo os índios"10. Essa missão não foi ao epicentro da transmissão da Covid-19 entre os Yanomami que, neste momento, era a CASAI.

O Presidente Bolsonaro criou uma disputa em torno do uso da cloroquina. Em suas declarações, ele insiste no uso desse medicamento, contrapondo-se aos riscos de seu uso para o tratamento da Covid-19 de acordo com vários especialistas que pesquisam sobre o tema e atuam em organizações como a Organização Pan-americana da Saúde (OPAS) ${ }^{11}$. Após a repercussão negativa sobre a distribuição desse medicamento, o SESAI emitiu uma nota no dia 3 de julho de 2020 afirmando que a cloroquina deveria ser utilizada para o tratamento de malária, mas "esqueceram" de enviar outro medicamento, a primaquina, mais utilizado no tratamento da malária falciparum, o tipo que prevalece na TI Yanomami, além de outros medicamentos que devem ser associados a esse ${ }^{12}$.

Após despejarem toneladas de comprimidos de cloroquina, que não são usados para conter a Covid-19, e ditarem formas de ser, viver e morrer por meio das restrições de biossegurança para a Covid-19, essas ações do governo federal pretendem ser humanitárias quando afirmam dos riscos de contágio e da preocupação dos mortos poderem disseminar o novo coronavírus em território. Mas esse travestir de humanitário escamoteia práticas violentas relativas à Covid-19 e a outros adoecimentos que proliferam em área.

Seguindo a trilha desses nós de violação, os Sanöma têm de lidar com a negligência que persiste em provocar outros adoecimentos em suas crianças. De acordo com os Sanöma, desde dezembro de 2020, não há o medicamento albendazol - fármaco indicado para o tratamento de verminoses, que estão atingindo especialmente as crianças no território Sanöma. A informação que obtive foi que ocorreu um erro na licitação de compra deste medicamento e os polos bases do DSEI-Y continuam sem

\footnotetext{
${ }^{10}$ Folha de Boa Vista "Ministro diz que pandemia está controlada nas terras indígenas". 01/07/2020.

${ }^{11} \mathrm{https}$ //www.paho.org/pt/covid19\#cloroquina-hidroxicloroquina

${ }^{12} \mathrm{https}: / /$ bvsms.saude.gov.br/bvs/folder/esquemas_recomendados_tratamento_malaria_naocomplicada.pd $\mathrm{f}$ 
esse medicamento ao logo desses seis meses. Os casos de verminoses em crianças estão se avolumando e agravando. Neste mês de maio de 2020, um Sanöma, quando esteve em sua comunidade, encontrou uma criança em estado grave de verminose: estava pálida, magra e vomitando vermes. Ele foi ao DSEI-Y solicitar uma caixa de albendazol, pegou essa caixa e encaminhou para os Sanöma em um voo de uma missão religiosa que seguiria para essa região. Esse não é o único relato de crianças em estado grave de verminose; os casos estão se multiplicando. Os Sanöma me alertaram que sempre aconteciam casos de verminoses, mas nada na quantidade que observam hoje. Eles conseguiam controlar os casos antes dos brancos adentrarem seu território, antes da década de 1960. Mas eles afirmam que com a presença dos brancos tudo se amplificou.

Pensar no conjunto de adoecimentos provocados pelas verminoses, doenças respiratórias, malária e covid-19, somado à potencialização da desnutrição infantil e do cenário de pais e demais familiares estarem também enfraquecidos e adoecidos, teremos uma explosão de mortes de crianças. Tragédias humanas estão sendo produzidas pelo atual governo. A vacinação contra o novo coronavírus aconteceu no território Sanöma eles tomaram as duas doses, exceto as comunidades que ficam mais distantes e precisam de deslocamento da equipe de saúde por meio de helicóptero. Os Sanöma preocupam-se com o fato de as crianças não poderem ser vacinadas contra a Covid-19, pois essas foram as maiores vítimas da Covid-19 e têm sido atingidas por outros adoecimentos.

\section{Finalizando o relato desses nós da trilha Sanöma ainda não desfeitos}

Ao longo desses 20 anos com os Sanöma, sem ter presenciado a epidemia das décadas de 1980 e 1990, nunca os tinha visto em uma situação tão extrema, com retorno de adoecimentos que estavam controlados. Poderíamos pensar que eles estavam em um processo de recuperação da epidemia de malária que os atingiu, mas, agora, estamos diante do somatório de epidemias: malária, covid-19, verminoses e desnutrição infantil. Os Sanöma são um povo altivo e não vão aceitar viver de esmolas da alimentação adoecida dos brancos - o que eles querem é seguir com suas vidas na interação com a floresta, pessoas e diversas criaturas que habitam o mundo, sob orientação dos xamãs e seus seres auxiliares e das mulheres e homens que manejam a vida cotidiana.

Eles afirmam a importância e lutam por um serviço de saúde estruturado em área, pois os brancos devem se responsabilizar pelas doenças que levaram para seu território. Portanto, as tecnologias de cuidado dos brancos devem alcançá-los. Afirmam, também, que algumas mercadorias dos brancos são hoje fundamentais para suas vidas, mas essas são inseridas por eles nas relações éticas que estabelecem com mundo. Eles não as usam na produção de genocídios e não aceitam que sejam usadas contra eles e a floresta.

O tempo é outro não há como voltar ao passado sem os brancos, aliás, suas réplicas já estavam refletidas nos sai töpö. Os xamãs sempre souberam da nossa existência e da possibilidade de terem que conviver 
com outras criaturas; a grande questão é que determinado jogo ético estava presente nesse contexto, aquilo que denominei como ética da moderação, desconhecida por muitos não indígenas.

Os Sanöma re-existem, nos termos de Segato (2018), e, no sentido que atuam na persistência de viver, afirmam sua humanidade e não apenas reagem, resistindo aos atos genocidas. Sob a atual gestão fica claro que a produção da vida ou da morte é informada pela filiação étnica/racial. Os Sanöma e os demais subgrupos Yanomami figuram como vidas precárias que estão sob ataque, vendo desfazer as condições materiais, sociais e existenciais de se fazerem (BUTLER, 2015). Para o atual governo, essas vidas não necessitam de proteção contra a violência, a fome ou pandemias. Para esses povos, viver é sempre viver uma vida que é vulnerável desde o início e que pode ser colocada em risco ou eliminada de uma hora para outra a partir do exterior e por motivos que nem sempre estão sob seu controle. A vida exige apoio e condições possibilitadoras para poder ser uma vida vivível (op cit.). Na lógica do atual governo, algumas vidas perdidas não são objeto de lamentação e as mortes de alguns são necessárias para a proteção da vida dos "vivos". O atual governo federal tem tomado decisões em relação a um ambiente que tornará ou não a vida vivível. No caso dos Sanöma, as ações de gestão que esse governo planeja, revelam essas decisões.

Essa é a letalidade da ordem capitalista, marcada em territórios indígenas pela expropriação do território, captura da autonomia dos sujeitos de fazer seu alimento, de cuidar. Está baseada na subordinação da vida e de sua reprodução ou recriação. Mas os Sanöma colocaram no centro dessa luta a vida, a floresta, os cuidados dos xamãs, os cuidados com suas crianças e com seus mortos e sua soberania alimentar. Essa é a luta estratégica para eles.

Conforme afirma Ailton Krenak (2020), os denominados quasehumanos são milhares de pessoas que insistem em ficar de fora dessa civilização, da técnica, do controle do planeta. Por isso são tirados de cena por epidemias, pobreza, fome e violência dirigida. Incomodam por apresentar outra possibilidade de vida. Gladys Tzul Tzul (2020) afirma que por toda a América Latina é possível ver os territórios indígenas como "arquipélagos políticos", como pequenas comunidades políticas que vivem e se antepõem à totalização do Estado. Essas comunidades existem expandidas, em escalas pequenas e ininterruptas em toda a América Latina, relacionadas por redes de troca. Após séculos de violência a autora (op cit) se impressiona com a energia dos povos indígenas em projetar essa energia para que a vida se refaça após tantos ataques. Vejo os Sanöma como um ponto dessa rede de arquipélagos projetando de maneira impressionante essa energia para a vida, criando na ética do cuidado e vivendo na ética da moderação. 
Espaço Ameríndio

\section{Referências bibliográficas}

ALBERT, B. Mortos sem sepultura. N-1 edições, 2020.

ALBERT, B. Indians lands, environmental policy and military geopolitics in the development of the Brazilian Amazon: the case of the Yanomami. Dev Change, vol, 23:35-70. 1992.

BASTA, P.; ORELLANA, J. Pesquisa sobre os determinantes sociais da desnutrição de crianças indígenas de até 5 anos de idade em oito aldeias inseridas no Distrito Sanitário Especial Indígena (DSEI) Yanomami, 2020.

BELLACASA, M. P. de la. Nothing comes without its world': thinking with care. The Sociological Review, 60:2, 2012.

BRUM, Eliane. Mães Yanomami imploram pelos corpos dos seus bebês. El País, 22 junho de 2020. https://brasil.elpais.com/brasil/2020-06-24/maes-yanomami-implorampelos-corpos-de-seus-bebes.html

BUTLER, Judith. Quadros de guerra: quando a vida é passível de luto? RJ: Civilização Brasileira, p. 13-55, 2015.

CARNEIRO, S. A Construção do Outro como não-ser como fundamento do ser. PósGraduação em Educação da Universidade de São Paulo. Tese de doutorado, 2005.

CÉSAIRE, A. Discurso sobre o colonialismo. Portugal: Livraria Sá da Costa Editora. 1978.

GUIMARÃES, S. Boletim Extraordinário CAAF/Unifesp de enfrentamento da Covid-19 - Mortos e Mortes da Covid-19, v. 1, p. 8-15, 2020.

GUIMARÃES, S. Agência das mulheres Sanöma e ativação de cosmopolítcas. Amazônica: revista de antropologia, v. 11, p. 583-605, 2019.

GUIMARÃES, S. O sistema médico sanumá-yanomami e a política de atenção à saúde indígena. Cadernos de Saúde Pública, Rio de Janeiro, 31(10):2148-2156, out, 2015.

GUIMARÃES, S. O drama ritual da morte nos Sanumá. Tellus, ano 10, n. 19, p. 111 128, jul./dez., 2010.

GUIMARÃES, S. Cosmologia Sanumá: o xamã e a constituição do ser. Tese de doutorado. Brasília: DAN/UnB, 2005.

KLEINMAN, A; VEENA DAS; LOCK, M. Social Suffering. Deadalus, vol. 125, n.1, 1996.

KOPENAWA, D. \& ALBERT, B. A Queda do céu: palavras de um xamã yanomami. SP: Companhia das Letras, 2015. 
Espaço Ameríndio

KRENAK, A. O amanhã não está à venda. SP: Companhia das Letras, 2020.

MATOS, L.; GUIMARÃES, S. Hospitalização de Pacientes Indígenas no DF/Brasil. In: Asensi, Felipe; Pinheiro, Roseni; Mutiz, Paula. (Org.). Saúde e Direitos Humanos. 1ed. Rio de Janeiro: Editora Multifoco, 2016, p. 397-408.

QUIJANO, A. Colonialidade do poder, Eurocentrismo e América Latina. In: A colonialidade do saber: eurocentrismo e ciências sociais. Perspectivas latinoamericanas. Buenos Aires: CLACSO, Consejo Latinoamericano de Ciencias Sociales, 2005

QUIJANO, A. ¡Qué tal raza!. Revista Venezolana de Economía y Ciencias Sociales, Vol. 6, $\mathrm{n}^{\mathrm{o}}$ 1, janeiro-abril, 2000.

ORELLANA. J.; MARRERO, L.; ALVES, C.; RUIZ, C.; HACON, S.; OLIVEIRA, M.; BASTA, P. Associação de baixa estatura severa em crianças indígenas Yanomami com baixa estatura materna: indícios de transmissão Intergeracional. Ciência \& Saúde Coletiva, 24(5):1875-1883, 2019.

PANTOJA, L.; ORELlANA, J.; LEIT, M.; BASTA, P. Cobertura do Sistema de Vigilância Alimentar e Nutricional Indígena (SISVAN-I) e prevalência de desvios nutricionais em crianças Yanomami menores de 60 meses, Amazônia, Brasil. Revista Brasileira de Saúde Materno Infantil. 14(1):53-63, 2014

RAMOS, R. Auaris revisitado. Série Antropológica 117, Brasília: Universidade de Brasília. 1991.

SANTOS, B. S. Pela Mão de Alice. São Paulo: Cortez Editora, 1995.

SEGATO, R. Contra-pedagogia de la crueldad. Buenos Aires: Prometeo Libros, 2018.

TZUL TZUL, G. Las mujeres indígenas reivindicamos una larga memoria de lucha por la tierra (entrevista), 3 abril de 2020. IN: https://www.revistaamazonas.com/2020/04/03/gladys-tzul-tzul-las-mujeres-indigenasreivindicamos-una-larga-memoria-de-lucha-por-la-tierra/

TZUL, TZUL, G. La forma communal de la resistência. In: Revista de La Universidade de México, no 3, pp. 105-111, 2019. 